\title{
Dematerialization through electronic media?
}

\author{
Coroama, Vlad C ; Moberg, Åsa ; Hilty, Lorenz M
}

\begin{abstract}
While the traditional roles of the computer as a machine for scientific calculations, text editing, and graphic design are still significant, computers are increasingly perceived as means of accessing information and interacting with other people - i.e., as electronic media. The aim of this chapter is to analyze digital electronic media and their effects on environmental sustainability. Two fields of application are addressed: electronic media that may replace or augment traditional print media such as newspapers or magazines, and videoconferencing as a potential substitute for traveling to a face-to-face meeting or conference. In both cases, the environmental costs of the electronic media are compared to those of their conventional counterparts. The examples show that electronic media can represent an energy-efficient alternative to traditional activities such as long-distance travel. But they can also be added on top of existing activities instead of replacing them. In such cases, a net increase in the environmental impact results. The availability of small, energy-efficient devices being used as electronic media does not guarantee dematerialization. The overall resource use and emissions throughout the life cycle of the media product systems and, more importantly, at the macro level of total global production and consumption need to be considered. To achieve the dematerialization potential of new electronic media solutions, their efficiency needs to be combined with sufficiency; thus additional measures are necessary to turn the dematerialization potential of electronic media into environmental relief.
\end{abstract}

DOI: https://doi.org/10.1007/978-3-319-09228-7_24

Posted at the Zurich Open Repository and Archive, University of Zurich

ZORA URL: https://doi.org/10.5167/uzh-109996

Book Section

Accepted Version

Originally published at:

Coroama, Vlad C; Moberg, Åsa; Hilty, Lorenz M (2015). Dematerialization through electronic media? In: Hilty, Lorenz; Aebischer, Bernard. ICT Innovations for Sustainability. Cham: Springer, 405-421.

DOI: https://doi.org/10.1007/978-3-319-09228-7_24 


\title{
Dematerialization through Electronic Media?
}

\author{
Vlad C. Coroama ${ }^{1}, \AA_{\text {sa }}$ Moberg $^{2,3}$, and Lorenz M. Hilty ${ }^{3,4,5}$ \\ ${ }^{1}$ Measure-IT Research, Bucharest, Romania \\ vlad.coroama@measureit-research.eu \\ ${ }^{2}$ Division of Environmental Strategies Research fms, KTH Royal Institute of Technology, \\ Stockholm, Sweden \\ asa.mobergeabe.kth.se \\ ${ }^{3}$ Centre for Sustainable Communications CESC, KTH Royal Institute of Technology, \\ Stockholm, Sweden \\ ${ }^{4}$ Department of Informatics, University of Zurich, Switzerland \\ hiltyeifi.uzh.ch \\ ${ }^{5}$ Empa, Swiss Federal Laboratories for Materials Science and Technology, Switzerland
}

\begin{abstract}
While the traditional roles of the computer as a machine for scientific calculations, text editing, and graphic design are still significant, computers are increasingly perceived as means of accessing information and interacting with other people - i.e., as electronic media. The aim of this chapter is to analyze digital electronic media and their effects on environmental sustainability. Two fields of application are addressed: electronic media that may replace or augment traditional print media such as newspapers or magazines, and videoconferencing as a potential substitute for traveling to a face-to-face meeting or conference. In both cases, the environmental costs of the electronic media are compared to those of their conventional counterparts. The examples show that electronic media can represent an energy-efficient alternative to traditional activities such as long-distance travel. But they can also be added on top of existing activities instead of replacing them. In such cases, a net increase in the environmental impact results. The availability of small, energy-efficient devices being used as electronic media does not guarantee dematerialization. The overall resource use and emissions throughout the life cycle of the media product systems and, more importantly, at the macro level of total global production and consumption need to be considered. To achieve the dematerialization potential of new electronic media solutions, their efficiency needs to be combined with sufficiency; thus additional measures are necessary to turn the dematerialization potential of electronic media into environmental relief.
\end{abstract}

Keywords: Electronic Media, Print Media, Videoconferencing, Virtual Meeting, Life Cycle Assessment, Environmental Assessment

This Accepted Author Manuscript is copyrighted by Springer. The final publication will be available via http://link.springer.com/bookseries/11156 by end of August 2014. Suggested citation: Coroama, V.C., Moberg, Å., Hilty, L.M.: Dematerialization through Electronic Media? In: Hilty, L.M., Aebischer, B. (eds.) ICT Innovations for Sustainability. Advances in Intelligent Systems and Computing 310. Springer International Publishing (2014, in press) 


\section{Introduction}

Today's electronic media are the result of a convergence of three lines of technological evolution. The first one is the development of technologies bridging space, i.e., extending the spatial range of communication, from flags and fires used for transmitting messages over some distance to the wires and electromagnetic waves we use today. The second one is the development of technologies for bridging time, i.e., extending the temporal range of communication, from carving messages to future generations into stone, writing and printing on paper to today's digital electronic storage. The third line, finally, runs from making calculations by moving limestone pebbles on a board (calculi in Latin, the origin of the verb calculate), using the abacus and mechanical calculators to the digital computer.

The final convergence of these three lines to digital Information and Communication Technology (ICT) created a new form of media we use to communicate, characterized by the possibility to transport information at almost zero cost through space and time. Before the convergence (roughly, before the emergence of the World Wide Web that made the Internet spread to every home), computers were machines we used for many other purposes, from solving numerical problems to playing chess and editing texts, but not for transporting messages through them to other people. The older role of the computer that dominated the pre-Internet age is of course still relevant but seems to be losing ground in the public perception. Most of the electronic media devices used today, such as smartphones or tablets, although they are computers with certain specific built-in peripherals and software, are no longer even perceived as computers by their users.

In this chapter, we will address two fields of media application:

- The media sector as the traditional domain of unidirectional media, delivering content in one direction, usually from one sender to many receivers.

- Videoconferencing as an application of bidirectional (or multidirectional) media, connecting two or more people in either direction.

The division into uni- and bidirectional as used here is also under transition and the media sector is today moving towards more bi- and multidirectional communication as well, with social media leading the way and more traditional media trying to make the best use of the possibilities provided.

In both cases we will investigate the environmental cost involved in the use of ICT-based media compared to that of their conventional counterparts (such as print media and face-to-face meetings). This cost can be assessed by investigating the life cycle of each medium, from the extraction of material resources and production of the consumer devices and the communication infrastructure used, to their use and disposal, including the effects of providing the energy needed in each phase. 
The convergence to digital ICT has dramatically changed media use and has created opportunities for, as well as threats to, sustainable development. Careful analysis of the current situation and future options is necessary to steer the development in the direction of sustainable (in particular dematerialized) media use.

\section{Electronic Media and the Media Sector}

\subsection{ICT Solutions for the Media Sector}

The media sector is an early adopter of ICT solutions. Over the 20th century, TV and radio were the major electronic media, but now a considerable increase and diversification of electronic distribution of content can be seen through desktop and laptop computers, followed by tablet computers and smartphones. These consumer devices are forming media content in new ways and also have considerable impact on people's media use practices. The yearly statistics for Sweden 2012 [1] show that one-third of the population (9-79 years) accesses newspapers, magazines, radio or TV (so-called traditional media) via the Internet on an average day [1]. In addition, almost $50 \%$ use social media and $21 \%$ watch video clips on the Internet [1].

In 2001 , during the evening ( $7 \mathrm{pm}$ to $10 \mathrm{pm}$ ), $73 \%$ of the Swedish population (979 years) watched television and 9\% used the Internet; in 2012 the figures were $63 \%$ and $33 \%$ respectively, which clearly illustrates ongoing changes in media use practice (see Fig. 1).

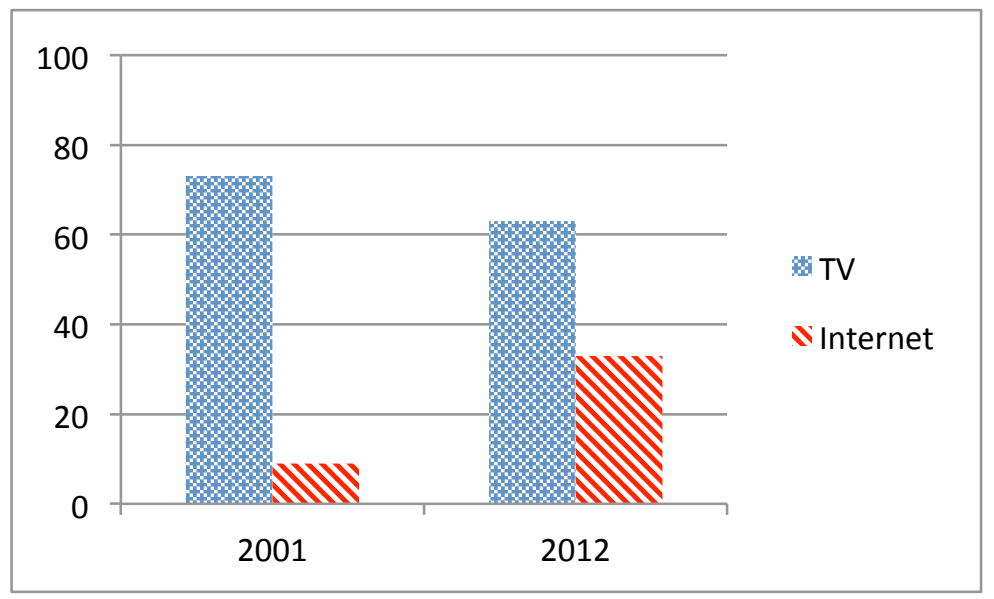

Fig. 1. A change in media use practice is illustrated here by the share of the Swedish population aged 9-79 who watched TV and used the Internet (based on [1]) between 7pm$10 \mathrm{pm}$. 
Changes taking place may offer opportunities for transitions towards sustainable media use practices. With the fast introduction and development of new ICT solutions for the media sector, an opportunity - and a major challenge - is to yield from this transition a positive result from an environmental perspective. The potential for ICT solutions to facilitate sustainable media practices needs to be actively developed. This implies that we learn about what the potential actually is and also about the possible disadvantages of an increased use of ICT solutions.

\section{Environmental Impacts of Electronic Media}

Several Life Cycle Assessment (LCA) studies of print media (e.g., [2-4]) and music on CDs [5] indicate that pulp and paper production for print media as well as the distribution of media products and potential personal transport needed to purchase or collect them are important contributors to their overall environmental impact. With the introduction of new dematerializing solutions where printed copies and CDs can be avoided, easily achieved environmental benefits could be anticipated by changing to electronic media. However, early comparative studies of traditional printed and new electronic media solutions indicated that the picture was more complicated (e.g., [6-9]). In spite of data gaps and rough assumptions, these assessments have offered analyses of the potential environmental impacts related to electronic media, which are in some sense less visible than those of traditional print media where the content needs its own physical substrate for distribution and the waste papers accumulate. The negative environmental impacts of electronic media were shown to be relevant as well and in some cases comparable or even larger than those of the traditional print media. This was an eyeopener to the media sector.

The direct environmental impacts of the electronic media solutions are to a large extent due to the manufacturing of the end-consumer devices and/or their usage [10]. These direct impacts, their magnitudes and their main causes are changing with the rapid development of ICT hardware. For the media sector, this is clearly illustrated by large and energy-demanding desktop computers with Cathode-Ray Tube (CRT) screens having been a common setting in the early 2000 s, while only 10 years later we carry one of the typical devices used for media content, the smartphone, in our pockets. Desktops, laptops and screens on the market in 2005 had the following electric power consumption in idle mode: desktop $78 \mathrm{~W}$; laptop $32 \mathrm{~W}$; CRT screen $70 \mathrm{~W}$; and LCD screen $31 \mathrm{~W}$ [11]. Some illustrative figures for the current 2014 consumption are for tablets around 3-5 W and laptops 6-17 W [12]. The consumption of e-readers lies in the sub-Watt region, as they only consume $3 \mathrm{~W}$ while "turning the page" (i.e., while refreshing the screen) and have zero consumption most of the time while text is being read. Even though the effect varies and can be higher or lower than in these examples, a trend can be observed towards lower input power for electronic devices used for accessing media, as they are to a greater extent mobile devices facing demand for longer battery life, while the energy density of batteries is limited. Furthermore, 
the manufacturing of smaller devices is generally causing less impact per device produced (see also the chapter by Hischier and Wäger [13] in this volume.)

However, the lifetime of devices is also a very important parameter, and the trend in this case is less beneficial. Remy and Huang ([14], in this volume) analyze the possibilities for the research field of Human-Computer Interaction (HCI) to provide solutions addressing obsolescence, which could be one way of counteracting this negative trend.

The trend towards decreasing lifetimes of products is in line with the overall increase in consumption in society, and a major problem with electronic media lies in the increasing diversity of devices being put on the market. We use several different electronic devices for consuming media content; in many cases we may use them for the same purpose/content, but in different locations or related to different activities. Together with decreasing lifetimes this leads to increased production and higher amounts of e-waste that have to be processed using methods that minimize environmental and social impacts (see the chapter by Böni et al. [15] in this volume). This makes the benefits less clear cut.

In assessing the direct environmental impacts of new electronic media solutions, these can be compared to those of traditional media products which they may substitute, such as printed books, newspapers and magazines. Some devices are specially designed to substitute for these, for example e-book readers which cannot be used for surfing the Internet. Others, such as smartphones and tablets, are multi-functional, and consuming media content is only one of several options for use. In the latter case the environmental impacts related to manufacturing and disposal are consequently allocated to several different activities. Also, the traditional media products have different characteristics, which are relevant to their environmental impact. Newspapers are printed on thin, low-weight paper, in contrast to magazines, which often have thicker and sometimes even glossy paper grades. Not all of the content in daily newspapers is read; the reader skips parts that are not interesting or for which he has no time, whereas in a book the reader tends to read the entire text.

Comparative environmental assessments have shown that different types of media products and different circumstances may imply a greater or smaller benefit, or drawbacks, from the introduction of ICT solutions. This can be, at least partly, explained by the characteristics mentioned above, e.g., a difference in total paper utilization in relation to overall reading time for printed media. The environmental impact related to electronic media increases as the use time increases, unlike printed media whose environmental impact is independent of reading time (if the light needed when reading is not accounted for).

Using the example of a daily newspaper, printed versions generally result in higher environmental impacts than the electronic version (e.g., [7,4,10]). A newspaper that is purchased or subscribed to implies a certain environmental impact related to the manufacturing, distribution and disposal of that newspaper. This impact is caused irrespective of whether the reader spends 1 minute or 45 minutes reading the paper. However, in considering the amount of time spent on 
printed or electronic newspapers, the environmental impacts of an electronic version may come close to or even be larger than those of the printed version, at least if the online newspaper is read from a desktop computer [4].

Similarly, in a study that compared the reading of e-books on an electronic reader with e-ink versus hardback literary books, the results clearly indicated a draw between the two options [9]. In this case, the reading time per book would be similar in both cases. As illustrated in Figure 2, the result is very much dependent on the number of printed books that are being substituted by the electronic reader.

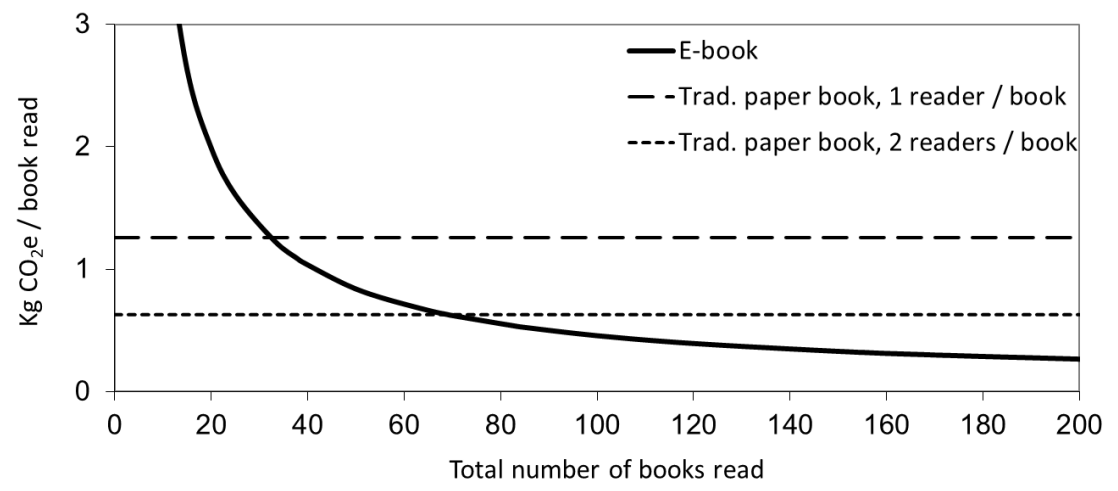

Fig. 2. Estimated greenhouse gas emissions per e-book as a function of total amount of ebooks read on an e-book reader [9]. The books assessed are a 360-page hardcover novel and a 1.5 MB PDF file, respectively. The books are bought, read and disposed of in Sweden. The impact of the paper book is shown for one and two readers per book.

Other studies of scholarly books have yielded quite contradictory results, with Enroth [8] presenting results in favor of printed books and Kozak [3] the opposite. The assessments differed in geographical scope as well as the characteristics of the books' studied. Enroth assumed each printed scholarly book to be used by five different pupils, and thus to be compared with $400 \mathrm{~h}$ of the use of a laptop or a desktop computer for reading an electronic version. With the assumption of only one pupil using the printed book, Kozak compared it with $32 \mathrm{~h}$ of reading the electronic version. Furthermore, in Kozak's case it was read from an e-reader device with LCD screen. This aptly illustrates the variation in the potential benefits or drawbacks from introducing ICT solutions for media content.

An LCA of two newspapers published by a Finnish media company clearly illustrated a source of difference between electronic newspapers [16]. One newspaper, with an emerging online version with rather few readers, showed that content production was important for the overall environmental impact. The other newspaper with a rather mature online version had higher downloads. Thus, the electronic distribution proved to influence the environmental impacts together with the manufacturing and the use of end-consumer devices, while the content production in this case was a minor factor [16]. Figure 3 shows the cumulated 
impact for all copies of the emerging and the mature online newspapers. For the mature e-paper with more copies, content production is roughly the same in absolute terms, but less important relative to the other sources of impacts.

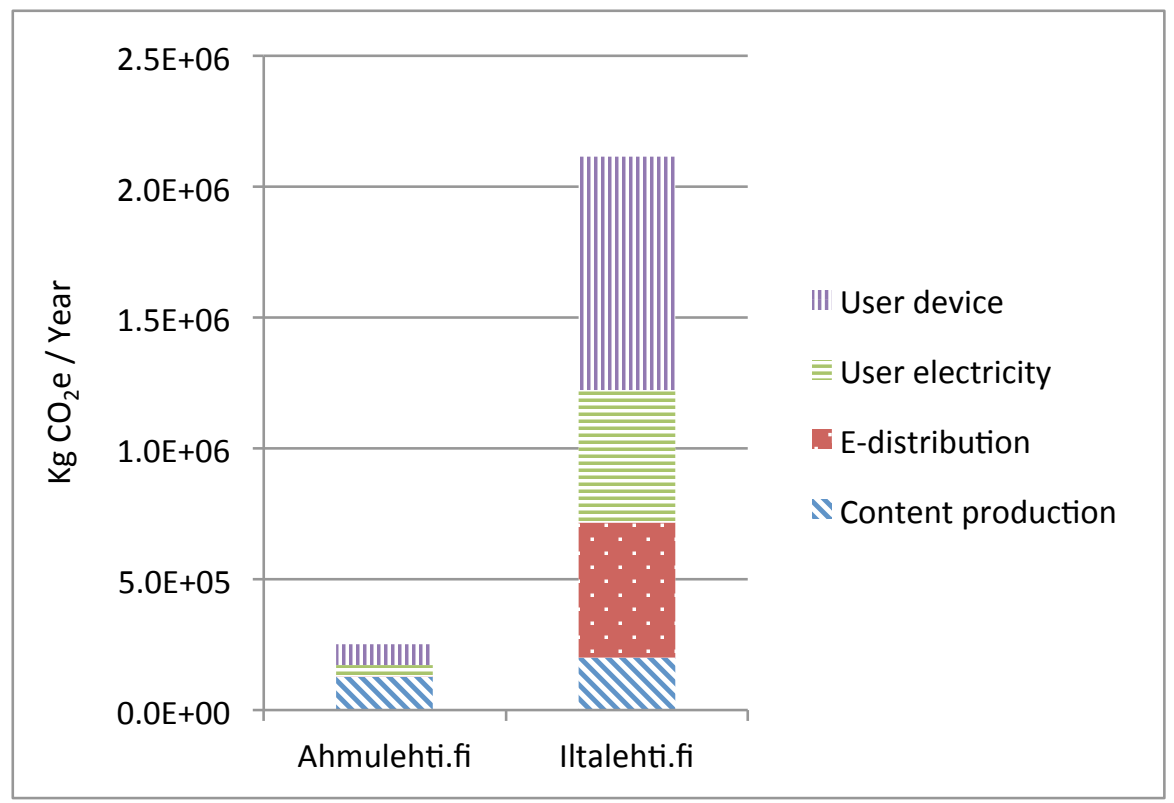

Fig. 3. Greenhouse gas emissions caused by two different Finnish online newspapers (based on [16])

Studies that distinguished between emerging and mature versions of electronic media $[17,16]$ pointed out that when electronic media is produced for a small number of consumers, the environmental impacts related to the content production become more important. This is because the impact is allocated to only a few consumers, and because at the same time the electronic end-user devices are getting smaller and more energy-efficient. With new media solutions making it possible to produce and distribute more diverse types of media to smaller audiences, the relatively large weight of the content production phase may become commonplace [16,17].

As devices become more efficient and if they are used sensibly, the environmental impacts from the electronic storage and distribution of the content may well become important too. In a study of a tablet magazine, the size of the electronic version was comparatively large and the average reading time per copy low; thus, the environmental impact of the electronic storage and distribution had a large influence on the overall environmental performance of the average tablet magazine [17]. In their comparison of this tablet magazine and its printed version, Achachloui and Moberg [18] illustrate that even with an efficient end-consumer device such as a tablet, the environmental impact may be higher for the electronic version than the printed one. This was the case when the overall number of readers 
of the tablet version was low. Large file size and low overall use of the tablet in this study also resulted in a higher impact for the tablet version compared to the printed one [18].

In addition, the early and widespread implementation of ICT solutions in the media sector may represent positive learning in terms of social practices and structural change, which may also be seen as a positive impact related to emerging technologies [19]. The introduction of new electronic devices triggered new media content and new media producers. Media content diversified and media content platforms are additionally used for communication. As Westlund [20] indicates, a smartphone today is used for personal and mass communication as well as to access information distributed personally or to a mass of people. If the use of ICTsolutions for media content encourage the use of ICT-solutions for other purposes and in other sectors (as people become comfortable with the tools and activities), many effects may ensue, both positive and negative. In this wider sense that includes induced behavior [21], the long-term environmental effects of the new media solutions and media practices are therefore difficult to foresee.

\subsection{Assessment Challenges}

Thus far, most of the existing environmental assessments focused on product-level direct impacts, challenging future studies to cover longer-term effects as well. For product-level assessments, many studies of electronic media have used rather uncertain inventory data due to lack of specific data $[22,10]$. This means that available, often generic, data are used and assumptions need to be made. This can result in both the underestimation and overestimation of impacts. Hischier et al. [23] distinguish between a "lab based" and a "desk based" strategy for modeling an ICT device. The former is based on dismantling the device and treating each component individually, while the latter makes use of available information on the component composition. Hischier et al. conclude that the "lab based" approach provides a more complete description of components. Still, if the data availability is insufficient for the components identified, estimations and assumptions will need to be made in any case in the next step. In a study of an e-magazine read from a tablet device, for example, the dismantling of an iPad2, identification of components, and connection to data available in the ecoinvent database lead to a result of $36.2 \mathrm{~kg} \mathrm{CO} 2$-eq. per device, while Apple reported $63 \mathrm{~kg} \mathrm{CO} 2$-eq. per device [17].

Assessments thus far have focused to a large extent on greenhouse gas emissions and energy use [10]. Energy-related resources and emissions are in general better covered in LCAs than are process-specific and material-specific impacts. This is an important limitation in the use of LCA for ICT solutions, where there are many different processes throughout the manufacturing of devices and components and where there are in many cases special requests for high purity of raw materials [24]. Assessments often note the high uncertainty or data gaps surrounding the disposal of the obsolete devices. Specific processes are used to 
handle e-waste, and a substantial part is handled informally in developing countries with considerable negative human and environmental impacts (e.g., $[25,26]$ and Böni et al. [15] in this volume). Generally, toxic emissions are relatively poorly covered in LCA [27], as are impacts related to biodiversity and land use, for example. This is a general difficulty in LCA, and one that is highly relevant to the assessment of electronic media solutions. This means extra efforts are needed to get a more complete understanding of the environmental impacts related to, for example, toxicological impacts, which are relevant for electronic media solutions.

Despite flaws and limitations in assessments of electronic media, especially when compared to paper media [22], increased knowledge has been gained. Drawbacks identified in the existing data have also encouraged the development of improved data sources, even though this development needs to be continued and intensified. One example where data is becoming more easily accessible and transparent is the energy intensity of the Internet (see the chapters by Coroama et al. [28] and Schien et al. [29] in this volume).

Some of the difficulties in assessing electronic media are related to user practices. The challenge here is inherent, as user practices cannot be foreseen and vary among users. This can be handled for example through sensitivity analyses or by presenting results for different persons. In so doing, the variation of environmental performance related to user practices can be made visible. This may also be one way of trying to illustrate how the potentials of new ICT solutions can be achieved and trying to encourage the development and use of devices facilitating sustainable practices.

\section{Virtual Meetings Substituting for Physical Meetings}

\subsection{Transporting Bits Instead of Atoms}

The technological convergence mentioned in Section 1 also opens the possibility of replacing physical meetings with virtual ones. From a sustainability perspective, it seems immediately plausible that sending images and sounds over fiber optics across the world is energetically more efficient than having people travel via cars and airplanes. Moving bits is easier than moving atoms.

This substitution effect is thus prominently mentioned as one of the main promises of ICT-induced energy efficiency and reduction of anthropogenic greenhouse gas (GHG) emissions. An optimistic industry vision, for example, predicted in 2008 that ICT could induce by 2020 a worldwide GHG reduction of $7.8 \mathrm{Gt} \mathrm{CO} 2 \mathrm{e}$, which corresponds to $15 \%$ of humankind's estimated business-asusual emissions in 2020 [30]. These reductions were to stem mainly from three domains: i) as a result of improved energy efficiency in the domains of smart engines, buildings, and logistics; ii) due to ICT-supported novel paradigms for the generation and distribution of electricity (i.e., smart grids); and iii) due to 
substitution effects, where ICT partly replace energy-intensive activities. Within this third domain, substituting data transfer for transportation to meetings (i.e., videoconferencing) and to work (i.e., telecommuting [31], not considered in this chapter) is seen as the substitution with the highest reduction potential. Studies on the energy intensity of the necessary data transmission have shown that such a substitution (apart from possible rebound effects) usually leads to dramatic energy and related GHG emission savings, as argued below.

Given the fact that the cost of virtual meetings is lower in terms of energy, the question should be asked if the benefit is the same as that of face-to-face meetings, in particular in terms of what may be termed "quality of communication." Varying qualities of communication between virtual and physical meetings, as well as among different technologies used for virtual meetings, could explain people's varying preferences for the types of meetings and the technologies used.

Takahashi et al. [32] analyzed the environmental effects of replacing business trips with videoconferencing, complementing the LCA of the two with a "value factor" for the quality of communication. Assuming that a virtual meeting is not a perfect replacement for a face-to-face meeting, they assigned a value factor of 0.6 to it, while using 1.0 for the face-to-face encounter. Even under this condition, the virtual meeting was only responsible for $20 \%$ of the emissions of the business trip for which it was substituted (400 kg instead of $2000 \mathrm{~kg} \mathrm{CO} 2$ ). The assessment of Toffel and Horvath [33] came to an even stronger conclusion, estimating that $\mathrm{CO} 2$ emissions for a business meeting held via teleconferencing are lower by 1-3 orders of magnitude compared to physical meetings. For obvious reasons, the number of participants and geographic distance are sensitive parameters in all studies of this type, and they largely account for the variation of the results.

Which ICT equipment is deployed for teleconferencing, how this equipment is used, and whether the use actually leads to less overall travel are nevertheless crucial factors for the net environmental effects. Borggren et al. [34] compare six teleconferencing scenarios (three different technologies combined with two usage intensities) with three types of physical travel (plane, car, and train). While for most cases, substituting videoconferences for travel leads to net energy and GHG savings, when high-end telepresence technology is used to substitute relatively short train travel (in Sweden roughly $450 \mathrm{~km}$ one-way), the energy use and greenhouse gas emissions may increase. This effect, however, only appears in two cases: First, in the low-usage scenario, when the telepresence system is used for only two hours per week and the production phase burden is thus distributed over a low usage for the entire lifespan.

Secondly, the effect also appears for the more intensive usage scenario of the telepresence system, but only in a sensitivity analysis using an Internet energy intensity value of $3.5 \mathrm{kWh} / \mathrm{GB}$ instead of the $0.42 \mathrm{kWh} / \mathrm{GB}$ from the baseline scenario. With this $3.5 \mathrm{kWh} / \mathrm{GB}$ assumption (adapted from [35] and [5] for 2010) the use-phase energy needed for data transmission dominates the Cumulative Energy Demand (CED) of the teleconference. As [36] shows, however, the topdown estimates in [5] and [35] include not only Internet network devices, but also 
data centers and LAN network devices in their calculations. The Internet energy intensity value used for the sensitivity analysis in [34] was thus unrealistically high.

Other studies examined the effect at the macro level for entire countries or regions. For all of Australia, for example, a replacement of one-third of the business trips by high-quality telepresence systems was estimated to reduce emissions by $2.4 \mathrm{Mt} \mathrm{CO}_{2} \mathrm{e}$ or around $0.4 \%$ of Australia's total emissions at that time [37]. If $30 \%$ of business trips worldwide were replaced by teleconferencing, it would lead to an estimated reduction of $500 \mathrm{Mt} \mathrm{CO}_{2} \mathrm{e}$ [30] - roughly $1 \%$ of global emissions.

These macro-level estimates usually assume that a 1:1 substitution takes place, i.e., they do not take into account rebound effects that may (partly) compensate for the substitution effect, because people will spend the time or money saved on trips either for additional trips or for other activities with relevant environmental impacts (see also Gossart [38], in this volume).

\subsection{The Case of Large International Conferences}

Hischier and Hilty [39] looked at the case of large international conferences. As a compromise between a traditional conference and a totally virtualized conference with participants sitting at their computers without the opportunity to enjoy the social aspects of conferencing, they suggested dividing a large international conference into several conferences, in particular with the aim of reducing the number of intercontinental flights.

This type of international conference was then organized in 2009, simultaneously in Switzerland and in Japan, and investigated with regard to its impact on participants and emissions [40].

Attendees could choose to travel to either one of the two venues: Davos, Switzerland, or Nagoya, Japan. Due to the time difference between the two regions, only part of the program could be shared; the morning workshops in Japan and the afternoon workshops in Switzerland were used for activities of more local interest. In the common 4-hour slot, however, all plenary sessions were shared among the two locations during the three conference days. The locations were connected via four high-definition "telepresence" streams, which included real-time audio, video, and slide sharing of the speaker, the audience of the other site, coffee break areas, and a small conference room that could be used, for instance, for workgroup meetings. This organization mode enabled not only the talks to be followed on the remote site, but also cross-continental Q\&A sessions, the creation of small workgroups across both sites, and informal chats during coffee breaks [40]. Figure 4 shows how the remote audience was seen by the local audience and the speaker. Figure 5 depicts how participants engaged in discussions during the breaks. 


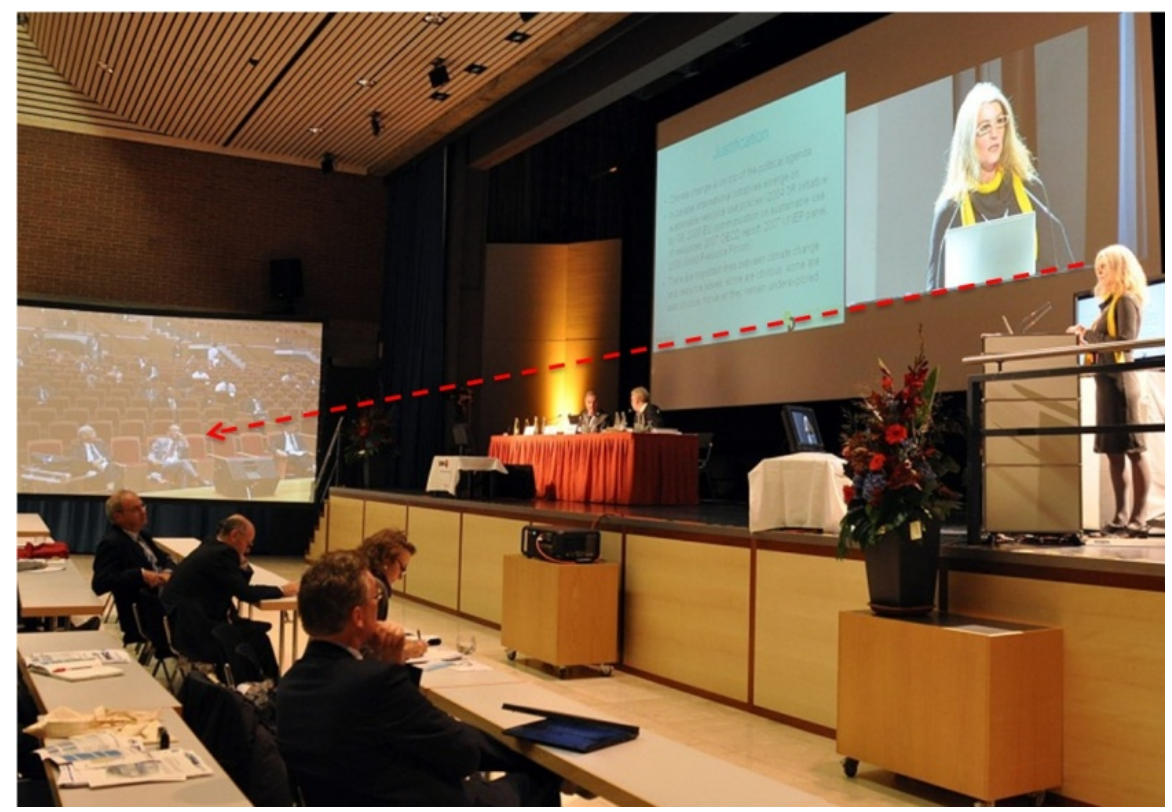

Fig. 4. The speaker engaging the local and the remote audience at a 45 degree angle each

After the conference, all attendees were invited to participate in a survey. They were asked about their satisfaction with the conference format (see [40] for the results) and the means of transportation they took to the conference. In order to assess their travel emissions, they were requested to precisely describe the legs of their journey and the respective means of transportation. A typical description was, for example, "airplane New York - Paris; airplane Paris - Zurich; train Zurich Airport - Davos." For each participant, the distances traveled on each leg and the resulting emissions could thus be computed. The participants were further invited to estimate whether they would have attended the conference had it been organized in a traditional mode only at the remote site (the site they had not traveled to). The hypothetical emissions for the travel to the remote site were computed conservatively assuming that attendees would have taken a train from their point of departure to the closest international airport, from there a direct flight to Zurich or Tokyo, respectively, and finally a train to Davos or Nagoya. 


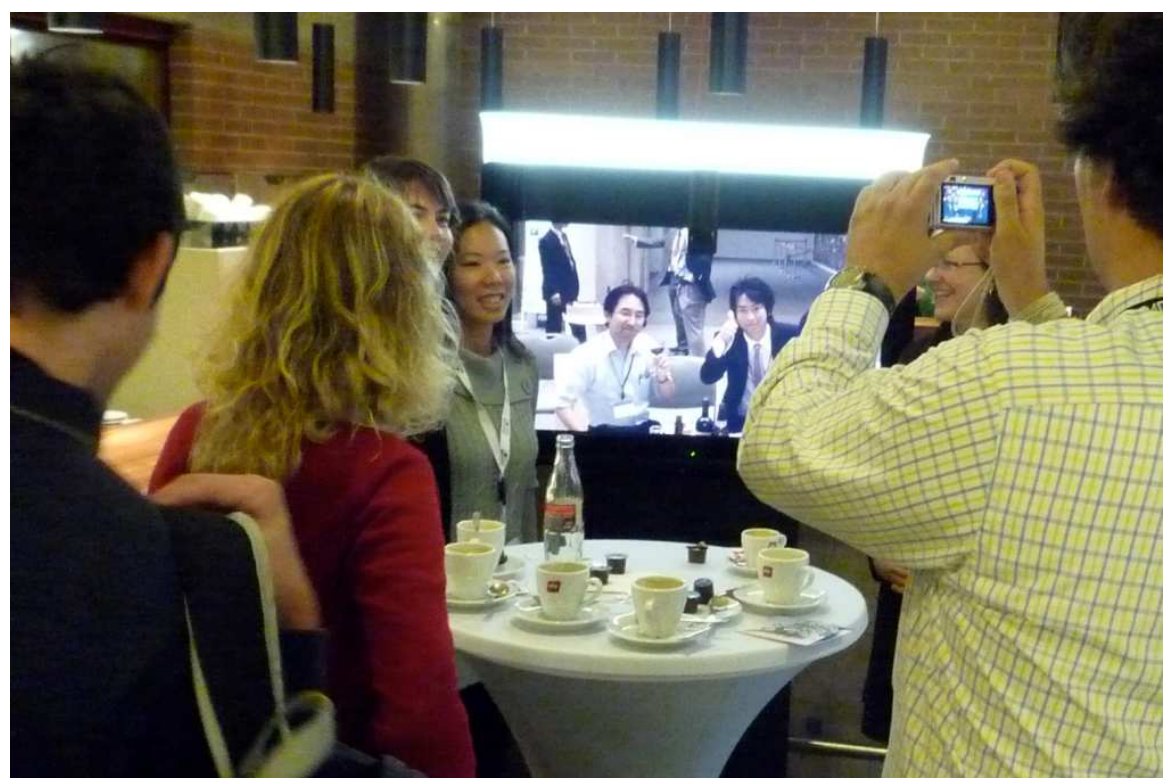

Fig. 5. Typical cross-site interaction during coffee breaks

Three alternatives could thus be compared: the two-site conference as it was held and the two hypothetical alternatives "Davos-only" and "Nagoya-only." The results are summarized in Figure 6:

- The Davos-Nagoya multiple-site conference had a total of 531 participants, 372 in Davos and 159 in Nagoya. Their travel caused 119 t of $\mathrm{CO}_{2}$ emissions, $84 \mathrm{t}$ for Davos and $35 \mathrm{t}$ for Nagoya.

- In the 'Davos-only' scenario, 448 attendees (the 372 from Davos plus another 76 from the Nagoya public) would have induced $235 \mathrm{t} \mathrm{CO}_{2}$

(84 $\mathrm{t}$ from the former participants plus a disproportionate $151 \mathrm{t}$ from the new attendees), almost double the $\mathrm{CO}_{2}$ emissions of the real scenario.

- In the 'Nagoya-only' scenario, a considerably reduced number of 238 attendees (159 'Nagoyans' and another 79 from Davos) would have produced 154 t CO$_{2}$, still more than those of the real scenario. Next to the $35 \mathrm{t}$ that would continue to be caused by the 159 Nagoya participants, the 79 new attendees would be responsible for another $154 \mathrm{t}$. This disproportionate impact would be due to their mainly international travel. 


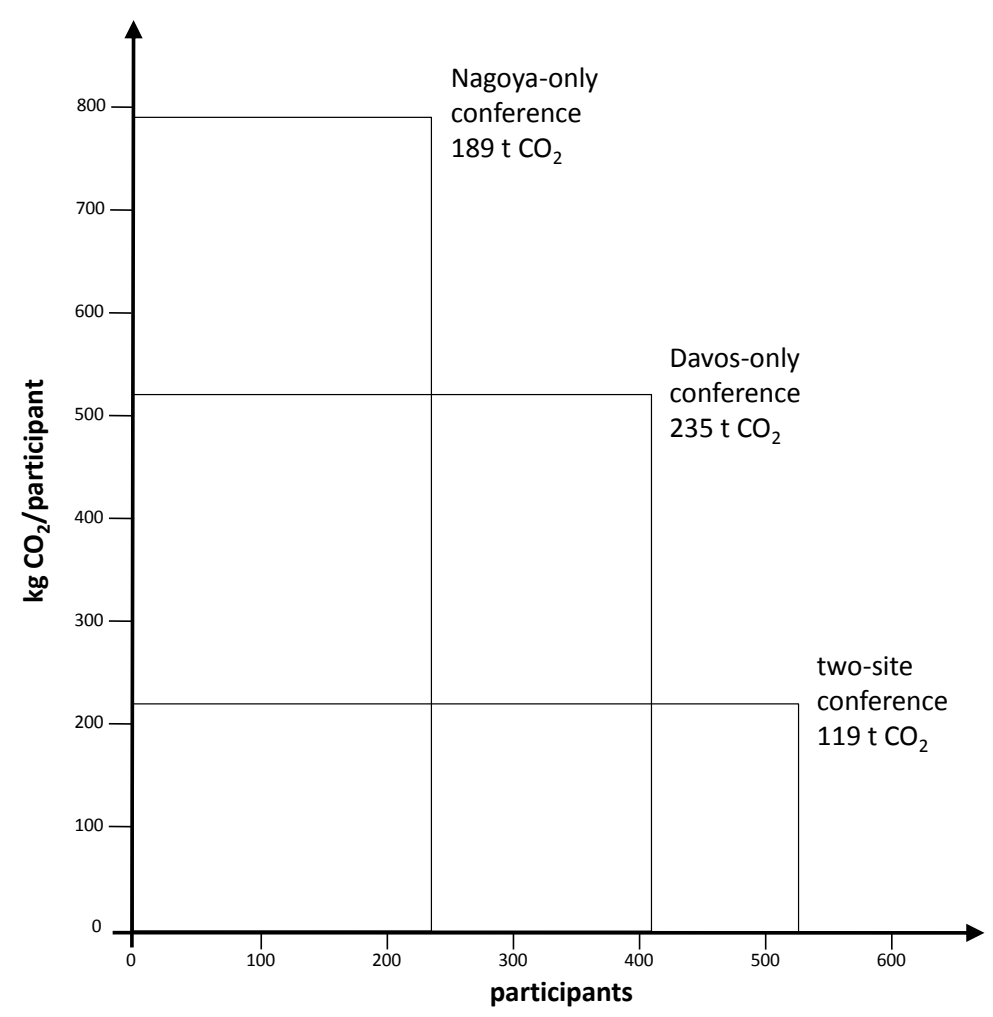

Fig. 6. Number of attendees and average per-capita emissions in the three possible conference scenarios. The surface of each rectangle represents the respective scenario's overall travel emissions. The multiple-site conference saved travel emissions as compared to both traditional alternatives, despite more overall attendees.

Compared to traditional organization modes, the distributed conference allowed on average quicker and less expensive travel for attendees. A significant rebound effect in terms of the number of participants was the unsurprising effect. Despite this rebound effect, the overall $\mathrm{CO}_{2}$ emissions caused by the travel of attendees were significantly reduced compared to the single-site alternatives. The relatively few avoided intercontinental flights (of participants in Europe or Asia who would have traveled to the remote site as well but had an alternative close to home) more than made up for the short trips of the many new participants who only took part because they had a venue close to home.

Allowing more attendees to take part while lowering the overall energetic costs meant that the reductions per participant were even higher - by a factor of 2.3 and 3.5 as compared to a 'Nagoya-only' and 'Davos-only' conference, respectively. Figure 7 summarizes the emissions per participant as well as the overall emissions for the three alternative organization modes. 


\section{Travel $\mathrm{CO}_{2}$}

腰 Total tons $\mathrm{N}$ Kg / attendee

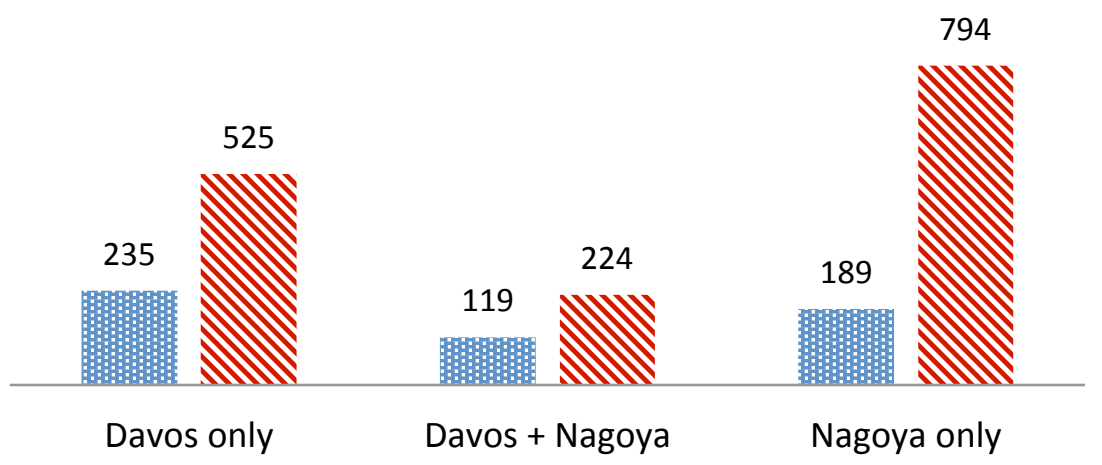

Fig. 7. Per participant and overall travel emissions in the three scenarios

\section{Conclusion and Outlook}

In introducing electronic media as a possible means of reducing environmental impact, it is important that these new solutions replace some other product or activity whose environmental impact can then be avoided. Even with some substitution taking place, numerous electronic media solutions are just added to what was there before. New types of media and new devices are continuously being created that can be used to consume media content as well as to communicate with others. More energy-efficient devices and communication networks need to be combined with sufficiency, not with increasing consumer demands [41].

Some new media solutions seem to inherently fulfill this condition. As it turns out from the field experiment presented in Section 3.2, the GHG emissions caused by an international conference can be reduced substantially by organizing it at multiple sites and thus reducing the average travel distance of the attendees. Even accounting for the rebound effect of increased participation, the overall $\mathrm{CO} 2$ emissions caused by the travel of attendees were significantly reduced compared to traditional alternatives.

For other types of new media (e.g., alternatives to print media), the picture is more complex. Even with increasingly energy-efficient devices, it is clear that considerable substitution is necessary to gain benefits, as well as increased utilization of devices over their lifetime and a decrease of the fast obsolescence of ICT gadgets. It is also important to consider environmental impacts other than greenhouse gas emissions.

As the main aim of a transition to new electronic media solutions is not to achieve more sustainable practices, the opportunity that this provides needs to be 
seized and actively managed. Action needs to be taken at different levels of society to achieve this, as "consumption choices are based not only on individual choices but also on existing and available infrastructure and on established social norms" ([41], p. 21). In order to foster environmental benefits from electronic media based on their dematerialization potential, the overall resource use and emissions throughout the life cycle of media product systems and more importantly at the macro level of total global media production and consumption need to be lowered. Adequate incentives are necessary and a variety of actors need to engage through policy-making in society and industry. Conscious design choices for hardware and software as well as increased awareness and informed choices among actors need to be encouraged. Electronic media is not a straightforward solution for dematerialization, but it can facilitate it if its potential is actively sought and unleashed.

\section{References}

1. Nordicom: Nordicom-Sveriges Internetbarometer 2012. En bearbetning av Mediebarometern 2012. In. Nordicom, (2013)

2. Gard, D.L., Keoleian, G.A.: Digital versus Print. Energy Performance in the Selection and Use of Scholarly Journals. Journal of Industrial Ecology 6(2), 115-132 (2002).

3. Kozak, G.: Printed Scholarly Books and E-book Reading Devices: A Comparative Life Cycle Assessment of Two Book Options. In., vol. CSS03-04. Center for Sustainable Systems, University of Michigan, (2003)

4. Moberg, Å., Johansson, M., Finnveden, G., Jonsson, A.: Printed and tablet e-paper newspaper from an environmental perspective - a screening life cycle assessment. Environmental Impact Assessment Review 30(3), 177-191 (2010).

5. Weber, C.L., Koomey, J.G., Matthews, H.S.: The Energy and Climate Change Impacts of Different Music Delivery Methods. In. Report to Microsoft Corporation and Intel Corporation, (2009)

6. Reichart, I., Hischier, R.: Environmental impact of electronic and print media: television, Internet newspaper and printed daily newspaper. In: Hilty, L.M., Gilgen, P.W. (eds.) Sustainability in the Information Society - 15th International Symposium Informatics for Environmental Protection 2001, pp. 91-98. Metropolis-Verlag

7. Reichart, I., Hischier, R.: The environmental impact of getting the news. A comparison of on-line, television, and newspaper information delivery. Journal of Industrial Ecology 6(3-4), 185-200 (2003).

8. Enroth, M.: Environmental impact of printed and electronic teaching aids, a screening study focusing on fossil carbon dioxide emission. In: Proceedings of the 36th International Research Conference of Advances in Printing Science and Technology, Stockholm, Sweden 2009, pp. 23-30

9. Moberg, A., Borggren, C., Finnveden, G.: Books from an environmental perspective Part 2. E-books as an alternative to paper books. The International Journal of Life Cycle Assessment 16(3), 238-246 (2011).

10. Arushanyan, Y., Ekener-Petersena, E., Finnveden, G.: Lessons learned - Review of LCAs for ICT products and services. Computers in Industry 65(2), 211-234 (2014). doi:10.1016/j.compind.2013.10.003 
11. IVF: Personal Computers (desktops and laptops) and Computer Monitors. Final report (tasks 1-8). In., vol. 07004. IVF, Industrial Research and development Corporation. , (2007)

12. Apple: Measuring performance. One product at a time. https://www.apple.com/environment/reports/ (2014).

13. Hischier, R., Wäger, P.A.: The Transition from Desktop Computers to Tablets: A Model for Increasing Resource Efficiency? In: Hilty, L.M., Aebischer, B. (eds.) ICT Innovations for Sustainability. Springer International Publishing (2014)

14. Remy, C., Huang, E.M.: Obsolescence of End-User Devices: Trends and Influencing Factors in Sustainable HCI. In: Hilty, L.M., Aebischer, B. (eds.) ICT Innovations for Sustainability. Springer International Publishing (2014)

15. Böni, H., Schluep, M., Petersen, E.E., Umair, S.: Recycling of ICT Equipment in Industrialized and Developing Countries. In: Hilty, L.M., Aebischer, B. (eds.) ICT Innovations for Sustainability. Springer International Publishing (2014)

16. Arushanyan, Y., Moberg, Å., Nors, M., Hohenthal, C.: Media content provided on different platforms - Environmental performance of online and printed versions of Alma Media newspapers. Journal of Print and Media Technology Research 3(1), 7-31 (2014).

17. Achachlouei, M.A., Moberg, Å., Hochschorner, E.: Life cycle assessment of a magazine - Part 1: Tablet edition in emerging and mature states. Journal of Industrial Ecology Accepted for publication (2014).

18. Achachlouei, M.A., Moberg, Å.: Life cycle assessment of a magazine - Part 2: A comparison of print and tablet editions. Journal of Industrial Ecology Accepted for publication (2014).

19. Sandén, B.A., Karlström, M.: Positive and negative feedback in consequential lifecycle assessment. Journal of Cleaner Production 15, 1469-1481 (2007). doi:10.1016/j.jclepro.2006.03.005

20. Westlund, O.: Mångfacetterad och oumbärlig: om mobilens roll i vardagslivet. In: Carlsson, U., Facht, U. (eds.) Mediesverige 2014. Statistik och analys. pp. 101-110. Nordicom, University of Gothenburg Göteborg, Sweden (2013)

21. Hilty, L.M.: Information Technology and Sustainability - Essays on the Relationship between Information Technology and Sustainable Development. Books on Demand Norderstedt (2008)

22. Bull, J.G., Kozak, R.A.: Comparative life cycle assessments: The case of paper and digital media. Environmental Impact Assessment Review 45, 10-18 (2014).

23. Hischier, R., Achachlouei, M.A., Hilty, L.M.: Evaluating the Sustainability of Electronic Media: Strategies for Life Cycle Inventory Data Collection and their Implications for LCA Results. Environmental Modelling \& Software 56, 27-36 (2014). doi:10.1016/j.envsoft.2014.01.001

24. Plepys, A.: The grey side of ICT. Environmental Impact Assessment Review 22(5), 509-523 (2002). doi:0.1016/S0195-9255(02)00025-2

25. Robinson, B.H.: E-waste: An assessment of global production and environmental impacts. Science of The Total Environment 408(2), 183-191 (2009). doi:10.1016/j.scitotenv.2009.09.044

26. Sepúlveda, A., Schluep, M., Renaud, F.G., Streicher, M., Kuehr, R., Hagelüken, C., Gerecke, A.C.: A review of the environmental fate and effects of hazardous substances released from electrical and electronic equipments during recycling: Examples from China and India. Environmental Impact Assessment Review 30(1), 28-41 (2010). doi:10.1016/j.eiar.2009.04.001 
27. Finnveden, G.: On the limitations of life cycle assessment and environmental systems analysis tools in general. The International Journal of Life Cycle Assessment 5(4), 229-238 (2000). doi:10.1007/BF02979365

28. Coroama, V.C., Schien, D., Preist, C., Hilty, L.M.: The Energy Intensity of the Internet: Home and Access Networks. In: Hilty, L.M., Aebischer, B. (eds.) ICT Innovations for Sustainability. Springer International Publishing (2014)

29. Schien, D., Coroama, V.C., Hilty, L.M., Preist, C.: The Energy Intensity of the Internet: Edge and Core Networks. In: Hilty, L.M., Aebischer, B. (eds.) ICT Innovations for Sustainability. Springer International Publishing (2014)

30. GeSI: SMART 2020: Enabling the Low Carbon Economy in the Information Age. www .theclimategroup.org/what-we-do/publications/smart2020-enabling-the-lowcarbon-economy-in-the-information-age/ (2008). Accessed Ocotober 2011

31. Horvath, A.: Environmental Analysis of Telework: What We Know, and What We Do Not Know and Why. In: IEEE International Symposium on Sustainable Systems and Technology (ISSST), Washington, DC, 17-19 May 2010 2010, pp. 1-3

32. Takahashi, K.I., Tsuda, M., Nakamura, J., Nishi, S.: Estimation of Videoconference Performance: Approach for Fairer Comparative Environmental Evaluation of ICT Services. In: Proceedings of the 2006 IEEE International Symposium on Electronics and the Environment, Scottsdale, AZ, US, 8-11 May 2006 2006, pp. 288-291

33. Toffel, M.W., Horvath, A.: Environmental Implications of Wireless Technologies: $\square$ News Delivery and Business Meetings. Environmental Science \& Technology 38(11), 2961-2970 (2004). doi:10.1021/es035035o

34. Borggren, C., Moberg, Å., Räsänenb, M., Finnveden, G.: Business meetings at a distance - decreasing greenhouse gas emissions and cumulative energy demand? Journal of Cleaner Production 41, 126-139 (2013). doi:10.1016/j.jclepro.2012.09.003

35. Taylor, C., Koomey, J.: Estimating Energy Use and Greenhouse Gas Emissions of Internet Advertising.

http://energy.lbl.gov/EA/emills/commentary/docs/carbonemissions.pdf (2008).

Accessed June 2010

36. Schien, D., Preist, C.: A Review of Top-Down Models of Internet Network Energy Intensity. In: Höjer, M., Lago, P., Wangel, J. (eds.) ICT for Sustainability (ICT4S), Stockholm, Sweden 2014

37. Mallon, K., Johnston, G., Burton, D., Cavanagh, J.: Towards a High-Bandwidth, LowCarbon Future: Telecommunications-based Opportunities to Reduce Greenhouse Gas Emissions. In. Climate Risk, Fairlight, Australia, (2007)

38. Gossart, C.: Rebound Effects and ICT: A Review of the Literature. In: Hilty, L.M., Aebischer, B. (eds.) ICT Innovations for Sustainability. Springer International Publishing (2014)

39. Hischier, R., Hilty, L.M.: Environmental Impacts of an International Conference. Environmental Impact Assessment Review 22, 543-557 (2002).

40. Coroama, V.C., Hilty, L.M., Birtel, M.: Effects of Internet-Based Multiple-Site Conferences on Greenhouse Gas Emissions. Telematics \& Informatics 29(4), 362-374 (2012). doi:10.1016/j.tele.2011.11.006

41. Tukker, A., Cohen, M.J., Hubacek, K., Mont, O.: The Impacts of Household Consumption and Options for Change. Journal of Industrial Ecology 14(1), 13-30 (2010). doi:10.1111/j.1530-9290.2009.00208.x 